\title{
Albania: another European country with the occurrence of Buchonomyia thienemanni Fittkau, 1955
}

\author{
Peter Bitušík \& Katarína Trnková
}

Department of Biology and Ecology, Faculty of Sciences, Matthias Belius University, Tajovsky street 40, 97401 Banska Bystrica, Slovakia.E-mail: peter.bitusik@umb.sk

Buchonomyia thienemanni is the only species within the subfamily Buchonomyiinae known from the western Palaearctic. Sæther \& Spies (2013) document the presence of this species in nine western and central European countries, as well as the Britain Islands and Corsica. Perhaps in part due to the unique and distinctive pupal exuviae, other recent studies have served to broaden the geographical distribution of this species. Specifically, recent reportings of B. thienemanni in the Czech Republic (Ashe et al. 2014) as well as Russia (Ashe et al. 2015) indicate that this species has a much broader distribution eastward and northward than previously anticipated.

Larvae and pupae of $B$. thienemanni are considered to be ectoparasites on Trichoptera (Ashe et al. 2015); however, other details on the ecology are not yet known. Therefore, B. thienemanni remains somewhat of a mysterious chironomid, leaving much room for continued study.

During our short stay in Albania in the summer of 2012, we collected floating chironomid pupal exuviae, pupae and drowned adults with a $250 \mu \mathrm{m}$ mesh hand net along the shores of several flowing and stagnant waterbodies. In the samples taken from the Shkumbin River in the central part of the country, two pupal exuviae (1 male, 1 female) of Buchonomyia thienemanni were found.

Full details of the record are as follows:

Locality: Albania, prefecture Elbasan, county Librazhd, 13 July, 2012, upper stretch of the Shkumbin River, $\sim 1.8 \mathrm{~km}$ downstream of Qukës, $413 \mathrm{~m}$ a. s. $1 . ; 41^{\circ} 05^{\prime} 17.0^{\prime \prime} \mathrm{N}, 20^{\circ} 26^{\prime} 48.6^{\prime \prime} \mathrm{E}$; leg. P. Bitušík \& K. Trnková. The sampling site can be characterised by swift turbulent flow, and stony bottom consisting of cobbles and boulders overgrown with considerable proportion of filamentous algae that could be indicative of high nutrient loading. The width of the river was on average $15 \mathrm{~m}$ and maximum water depth reached 70 cm during time of the sampling (Fig. 1).

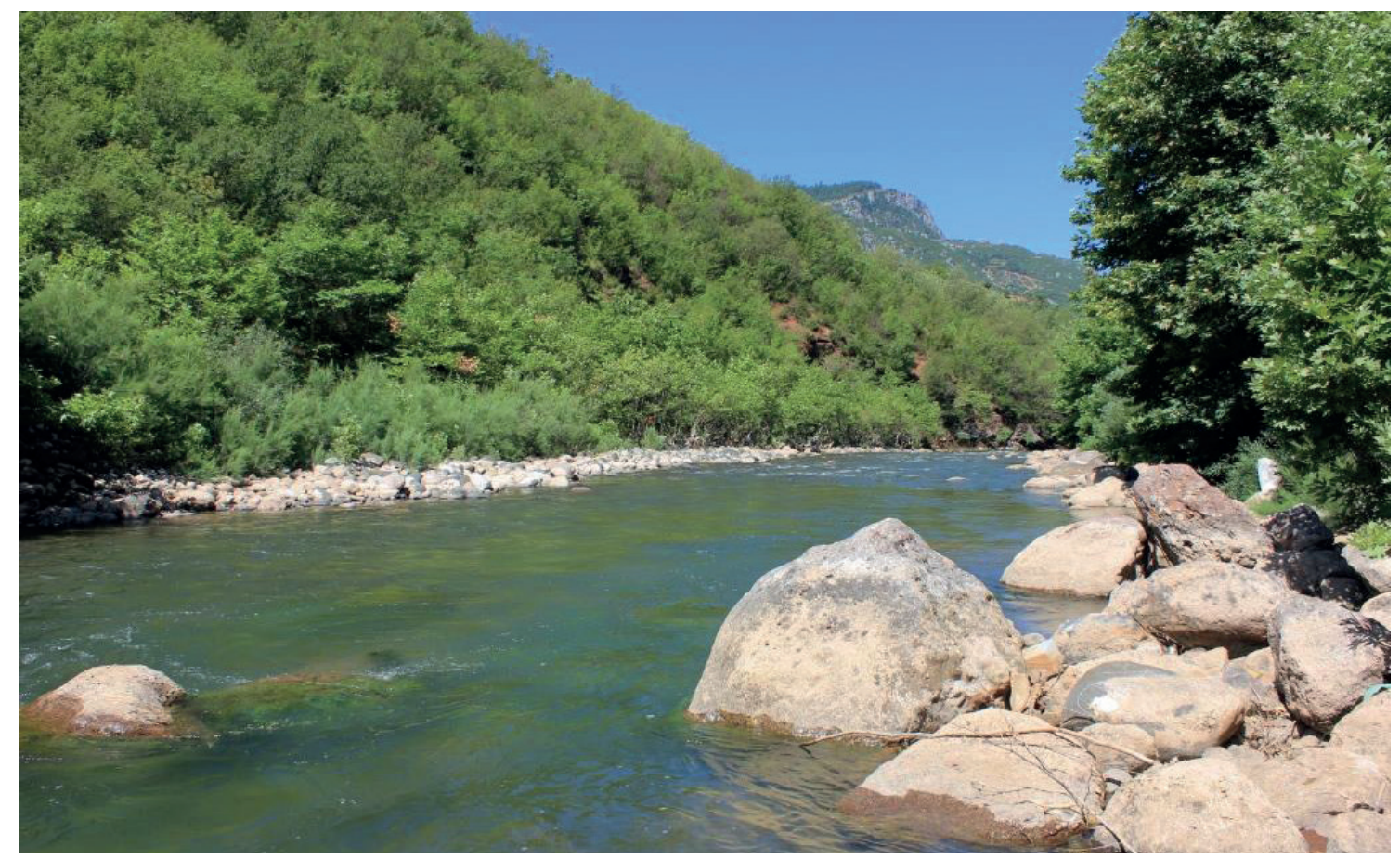

Figure 1. Shkumbin River, view of the sampling site of B. thienemanni. Photo: K. Trnková 
Voucher specimens have been mounted on microscopic slides using Berlese fluid and deposited in the collection of the Department of Biology and Ecology, Faculty of Science, Matthias Belius University in Banská Bystrica.

The finding of B. thienemanni in Albania is significant as it is the first record of the species in the Balkans. Characteristics of the sampling site partly support the findings of other authors (e.g. Marziali et al. 2009, Ashe et al. 2014) that the species inhabits shallow, well-oxygenated streams with firm substrate in lower parts of the rhithral zone, and is able to tolerate moderate levels of pollution.

\section{References}

Ashe, P., Moubayed-Breil, J. \& Vondrák, D. (2014). First records of Buchonomyia thienemanni Fittkau (Diptera: Chironomidae) from the Czech Republic. CHIRONOMUS Journal of Chironomidae Research, 27: 51-53. DOI: http://dx.doi.org/10.5324/cjcr.v0i27.1711

Ashe, P., O'Connor, J. P. and Murray, D. A. (2015). A review of the distribution and ecology of Buchonomyia thienemanni Fittkau (Diptera: Chironomidae) including a first record for Russia. European Journal of Environmental Sciences, 5(1): 5-11. DOI: http://dx.doi.org/10.14712/23361964.2015.69

Marziali, L., Casalegno, C. and Rossaro, B. 2004. The first record of the subfamily Buchonomyiinae (Diptera, Chironomidae) from Italy. Italian Journal of Zoology, 71(4): 341-345. DOI: http://dx.doi. org/10.1080/11250000409356593

Sæther, O. A. and Spies, M. 2013. Fauna Europaea: Chironomidae. In Beuk P. \& Pape T. (eds.): Fauna Europaea: Diptera, Nematocera. Fauna Europaea version 2.6, http://www.faunaeur.org

Article submitted 25. July 2016, accepted by Alyssa M. Anderson 25. September 2016, published 28. October 2016. 